\title{
Effects of longterm epidermal growth factor treatment on the normal rat colon
}

\author{
P Kissmeyer-Nielsen, L Vinter-Jensen, M Smerup
}

\begin{abstract}
Background-Epidermal growth factor (EGF) exerts trophic effects on the mucosa of damaged and defunctioned colon, but the effects on the normal large bowel wall are not known.

Aims-To investigate the effect of systemic EGF treatment on growth and morphology of normal rat colon.
\end{abstract}

Methods-Rats were treated with subcutaneous biosynthetic EGF injections of $150 \mu \mathrm{g} / \mathrm{kg} /$ day for 28 days. The weight of the histological colonic wall layers and the luminal surface area were measured using quantitative morphometric analysis (stereology). The colon was subdivided into proximal and distal parts.

Results-EGF treatment increased the total colon wet weight by $23 \%$ compared with controls $(\mathbf{p}<0.005)$. The weight increase occurred in the mucosal $(33 \%)$ and the submucosal layers of the bowel wall $(36 \%)$ and there was a $69 \%$ increase of the total luminal surface area $(p=0 \cdot 001)$. In the proximal part of colon of EGF rats there was a $68 \%$ increase in mucosal weight $(p<0.005)$ accompanied by a $79 \%$ increase in the mucosal surface area compared with controls $(p<0 \cdot 005)$, whereas submucosal and muscularis propria weights were identical. In distal colon, the mucosal weight increased $28 \%$ in the EGF group $(p<0 \cdot 005)$, the mucosal surface area increased by $72 \%$ after treatment $(p<0.01)$. Furthermore there was a $34 \%$ increase in the weight of submucosa $(p<0.001)$ in the distal colon among EGF rats.

Conclusions-Treatment of rats with EGF has a stimulating role on the mucosa and luminal surface area of the entire functioning colon and a trophic effect on the submucosa of the distal colon.

(Gut 1996; 38: 582-586)

Keywords: epidermal growth factor, rat, colon growth, stereology.

Epidermal growth factor (EGF) is a polypeptide chain consisting of 53 amino acids that belongs to an expanding group of growth factor ligands. ${ }^{1}$ The EGF family and their related receptors are widely distributed in mammalian species and they play an important part in the growth and differentiation of normal, regenerative, and neoplastic tissues. ${ }^{2}$ EGF is a powerful mitogen and trophic agent in many tissues including the gastrointestinal tract. The EGF effects are believed to be mediated through stimulation of the polyamine synthesis, as EGF upregulates ornithine decarboxylase activity in the epithelial cells. ${ }^{2} 3$

Human recombinant EGF is now available and treatment potentials have been investigated in various organ systems. ${ }^{2}$ In experimental studies, systemic treatment with EGF has been shown to attenuate ulceration or other types of experimental damage to the gastrointestinal tract and to accelerate the healing of such lesions. ${ }^{3-5}$ In the colon, EGF has a protective effect on the mucosa after trinitrobenzenesulphonic acid (TNB) induced colitis in rats ${ }^{67}$ and EGF increases intestinal anastomotic tensile strength in pigs. ${ }^{8}$ Reports also exist of EGF use in serious clinical conditions; a case of necrotising enteritis and several cases of congenital microvillous atrophy. ${ }^{9-11}$

Several in vivo growth promoting actions of $\mathrm{EGF}$ on the gastrointestinal tract remain unclear. EGF treatment reduces gut atrophy in the defunctioned rat colorectum and during total parenteral nutrition, ${ }^{12-14}$ but the effects of systemic EGF on normal colon have not been investigated. The aim of this study was to evaluate the influence of four weeks of systemic EGF treatment on the undamaged rat colon. The colonic wall composition and luminal surface area were investigated using modern stereological techniques. ${ }^{15}$

\section{Methods}

\section{Study animals}

The study protocol was conducted on 16 male Wistar rats from our own breed approximately eight weeks old and weighing 155-255 grams. The animals were housed as $21^{\circ} \mathrm{C}$ and fed a standard laboratory diet. All procedures were carried out in accordance with the Danish law on care and use of laboratory animals.

\section{Study design}

The animals were randomly allocated into a treatment group receiving human recombinant EGF (Upstate Biotechnology, New York, USA) and a placebo group receiving isotonic saline. Injections were given subcutaneously twice daily and a total dose of $150 \mu \mathrm{g} / \mathrm{kg} /$ day EGF was given in the treatment group. All the procedures were conducted in a blinded fashion.

\section{Tissue sampling}

After 28 days of treatment the animals were transcardially perfused under Mebumal anaesthesia at a pressure of $120 \mathrm{~mm} \mathrm{Hg}$ with 
Figure 1: Test line system of cycloids and test points on a vertical section of the distal colonic wall (Van Gieson, original

magnification: $\times 180$ )

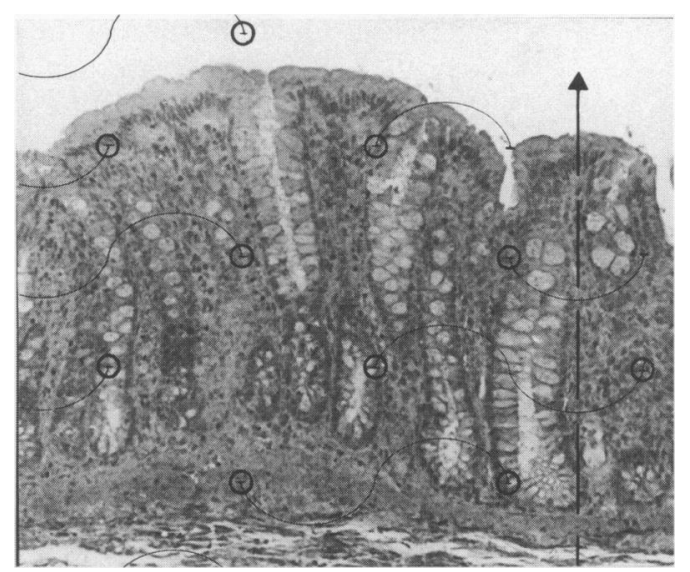

isotonic saline $(50 \mathrm{ml})$ followed by phosphate buffered formaldehyde $(300 \mathrm{ml} ; 4 \%, 0 \cdot 1 \mathrm{M}$,

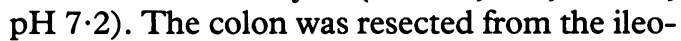
caecal valve (excluding the caecum) to the anal canal, slit open, and divided into proximal and distal colon segments. The segregation between proximal and distal colon was made where the mucosa of major flexure passes over into distal colon. ${ }^{16}$ Each segment was rinsed and weighed. Four or five small sections were sampled from the proximal and the distal colonic segments respectively. The position of the first sample was random within the first centimetre of the proximal or distal end of each segment, and the following sections were sampled at one centimetre intervals. All specimens were used for stereological estimation of colonic wall composition and mucosal surface area of the segments and the entire colon.

\section{Stereology}

The stereological methods are based on 'vertical sections' and have previously been described in detail. ${ }^{15} 17$ The colonic sections were rotated randomly on their flat peritoneal surface and kept flat during embedding in glycol-methacrylate (Technovit 7100, Kulzer Histo-Technik, Axel Johnson Lab System $\mathrm{A} / \mathrm{S}$ ), which was used to minimise tissue shrinkage. ${ }^{18}$ The embedded sections were cut perpendicular to their flat surface ${ }^{15}$ and sections were stained with van Gieson.

For determination of the volume fractions (VF) of the colonic wall layers, sections were magnified $\times 310$ and projected (Olympus $\mathrm{BH}-$ 2, Tokyo, Japan) at random onto a grid with regularly arranged points. The number of points hitting the mucosa $\left(P_{\text {mucosa }}\right)$, the submucosa $\left(\mathbf{P}_{\text {submucosa }}\right)$, and the muscularis propria $\left(P_{\text {muscularis }}\right)$ were counted in 24 fields of

Wet weight of total colon, the separate histological layers, and the luminal surface area in rats treated with $150 \mu \mathrm{g} / \mathrm{kg} /$ day EGF or placebo for 28 days

\begin{tabular}{llll}
\hline & EGF & Placebo & p Value \\
\hline Total colon (mg) & $2683(3162-2415)$ & $2177(2432-1879)$ & $\dagger$ \\
$\quad$ proximal colon (mg) & $1462(1059-1793)$ & $1085(893-1397)$ & $\star$ \\
distal colon (mg) & $1361(1029-1543)$ & $1060(1160)$ & $\star$ \\
Mucosa (mg) & $1712(1572-1898)$ & $1283(1027-1326)$ & $\dagger$ \\
Submucosa (mg) & $480(374-586)$ & $354(241-487)$ & $\star$ \\
Muscularis propria (mg) & $557(435-765)$ & $556(494-667)$ & $0 \cdot 73$ \\
Luminal surface area (cm $\left.{ }^{2}\right)$ & $67 \cdot 2(52 \cdot 3-72 \cdot 7)$ & $39 \cdot 8(34 \cdot 4-50 \cdot 2)$ & $\dagger$ \\
\hline
\end{tabular}

Median (range). ${ }^{\star} \mathrm{p}<0.05,{ }^{\star \star} \mathrm{p}<0.01$, and $\mathrm{tp}<0.005, \mathrm{EGF} v$ placebo. vision selected evenly among the sections from each colon segment. Points hitting the small amounts of serosa, mesenterical fat, or lymphoid tissue were counted separately $\left(P_{\text {extra }}\right)$. The separate counts were totalled to obtain the total number of points $\left(\mathbf{P}_{\text {total }}\right)$ for every field, which was used to calculate the VF of, for example, the mucosa:

$$
\text { VF (mucosa): } \Sigma P_{\text {mucosa }} / \Sigma P_{\text {total }}
$$

The VF of each layer was multiplied with the wet weight (WW) of corresponding segments to determine the weight of, for example, the mucosal layer:

weight of mucosa: VF (mucosa) $\times \mathrm{WW}$ (segment)

A specific density of all layers of $1.0 \mathrm{~g} / \mathrm{cm}^{3}$ was assumed. The WW constitutes the reference volume (weight). The sum of VF in each animal from proximal and distal segments were multiplied by the total colon weight to determine the weight of the wall layers in the entire colon. This procedure was repeated at a higher magnification $(\times 620)$ on the mucosal layer to differentiate it into weight of epithelium, lamina propria, and muscularis mucosae. ${ }^{15}$

The mucosal surface area was estimated using a frame with a test line system of cycloids and test points (line length per point $l_{p}=14.5$ $\mathrm{cm})$. Intersections between cycloids and the borderline between the colonocytes of the epithelium and the lamina propria (I) were counted in 24 fields of vision chosen evenly between the four sections from each segment (Fig 1). Test points hitting the mucosal layer were also counted $(P)$ and included in the mucosal surface area calculation ${ }^{19}$ :

$$
\text { surface area: } \Sigma \mathrm{I} / \Sigma \mathrm{P} \times 2 / \mathrm{l}_{\mathrm{p}} \times \mathrm{V}_{\text {ref }}
$$

The mucosal weight was calculated previously and constituted the reference volume (weight) $\mathrm{V}_{\text {ref }}$.

\section{Statistics}

The non-parametric Mann-Whitney two sample test was used for comparison between groups, and probability values less than 5\% were considered significant. Results are given as median values.

\section{Results}

Animals in both treatment groups thrived throughout the study. There were no weight differences between the groups during the experiment. Blood samples were taken from the periorbital plexus in ether anaesthesia after two weeks and in the Mebumal anaesthesia after four weeks. The results of these tests are described elsewhere. ${ }^{20} \mathrm{~A}$ single animal in the placebo group died during the anaesthesic procedure after two weeks.

\section{Total colon}

As the Table shows, EGF treatment increased the median total colon wet weight by $23 \%$ compared with the median weight of colon in 


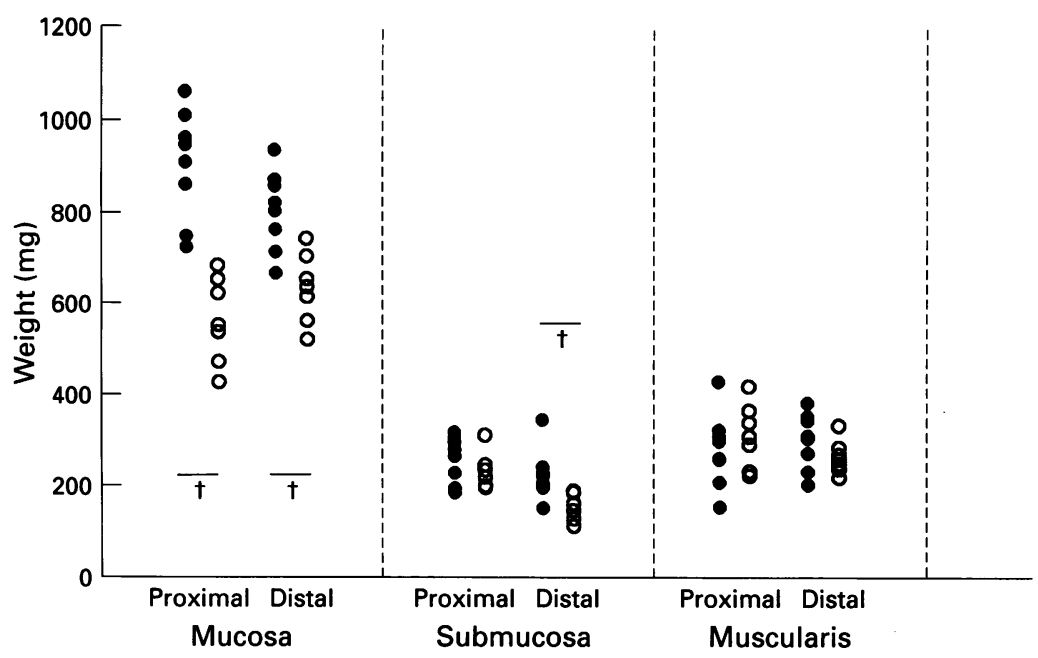

Figure 2: Histological composition of colon. Weight of the mucosa, submucosa, and muscularis propria in proximal and distal colon after treatment with EGF (๑) and placebo (0) for 28 days. $t p<0.005 E G F \mathrm{v}$ placebo.

control rats $p<0.005)$. The stereological analysis showed that the colonic growth after EGF treatment was caused by a $33 \%$ increase in mucosal weight $(p<0.995)$ and a $36 \%$ increase in the submucosal weight $(p=0.01)$. The luminal surface area was increased by $69 \%$ $(p=0.001)$ in colon from EGF rats compared with controls (Table).

\section{Proximal colon}

Colon segments proximal to the major flexure were increased $35 \%$ in wet weight compared with controls $(\mathrm{p}<0.01)$ (Table). Analysis showed that the weight increase was caused by growth exclusively in the mucosal layer, where the median weight was $68 \%$ higher among EGF treated rats $(\mathrm{p}<0.005)$ than in controls (Fig 2). This was accompanied by a $79 \%$ increase $(p<0.005)$ in luminal surface area (Fig 3). The weight of submucosa and muscularis propria were similar in the two treatment groups in proximal colon (Fig 2).

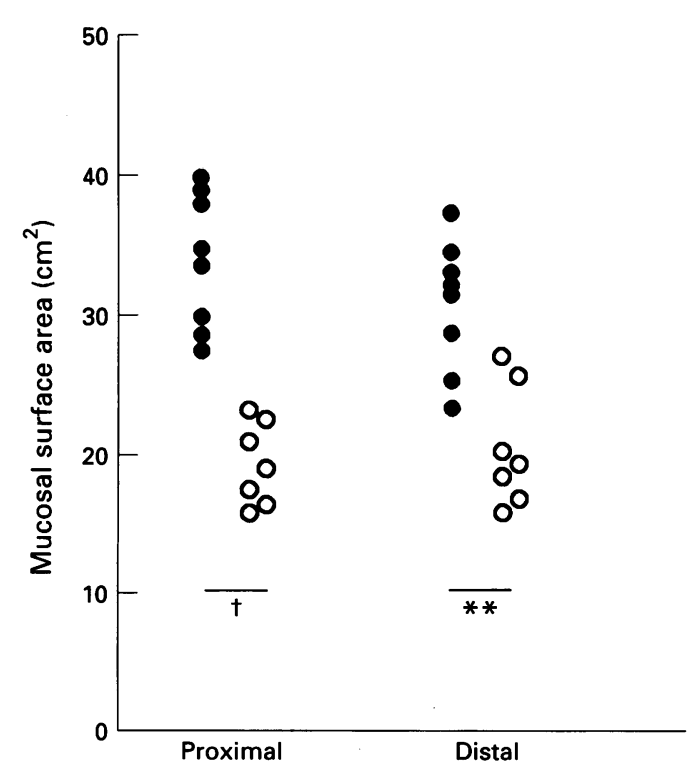

Figure 3: Luminal surface area in proximal and distal colon after treatment with EGF (৫) and placebo (O) for 28 days. ${ }^{\star \star} p<0.01,+p<0.005$ EGF v placebo.
Quantification of the mucosa (Fig 4) showed a $64 \%$ increase in the epithelium layer $(p<0.005)$ and a $64 \%$ increase in the weight of lamina propria $(p<0.005)$. The muscularis mucosae layer is very thin in the proximal part of the rat colon, and we found no difference in the weight of this delicate layer between groups.

\section{Distal colon}

The median wet weight of distal colon segments was increased by $28 \%$ in EGF rats compared with controls $(p<0.05)$ (Table). In these segments the EGF induced mucosal growth was $28 \%$ compared with mucosa in controls $(p<0.005)$ (Fig 2), and seemed less prominent than in proximal colon. The mucosal surface area was increased by $72 \%$ $(p<0.01)$ compared with controls (Fig 3). In the distal colon we found a substantial $34 \%$ increase in the weight of submucosa among EGF treated rats $(p<0.001)$, while the weight of muscularis propria, as in proximal segments, were equal in the two groups. In the mucosa we found a significant $50 \%$ increase in the weight of epithelium among EGF rats $(p<0.005)$ and a $51 \%$ increase of muscularis mucosae, where the difference just reached the level of significance $(p=0.049)$. There was a non-significant $20 \%$ increase in the lamina propria weight $(p=0.064)$ compared with controls (Fig 4).

For each animal, the weight of proximal mucosa was compared with the weight of distal mucosa to obtain a proximal/distal mucosal ratio in the two treatment groups. This ratio was calculated to further examine the EGF effect on the colonic mucosa and to verify statistically, if there is a diverse response in mucosa of proximal and distal colon to EGF treatment. Figure 5 shows the results and the proximal/distal mucosal ratio tended to be increased in the EGF group $(p=0 \cdot 07)$.

\section{Discussion}

Previous investigations of systemic EGF actions on the colon have focused on the defunctioned or damaged intestine. Foster et al showed that intravenous EGF for 10 days maintained colonocyte proliferation at a normal rate in surgically defunctioned colorectum in rats. ${ }^{12}$ Also in rats, EGF was shown to preserve epithelial proliferation in the colon during total parenteral feeding for eight days, ${ }^{13}$ and in recent studies to protect against mucosal lesions caused by experimental colitis. ${ }^{67}$ These and comparable studies have unambiguously proposed EGF as a trophic factor in the maintenance of epithelial proliferation in colon. This study is the first to describe the trophic effects of systemic EGF treatment on all the large bowel wall layers and on the luminal surface area of normal functioning colon. It shows that EGF stimulates growth of the mucosal layer and the luminal surface area in both proximal and distal colon and that EGF also has a trophic effect on the submucosa in the distal part of the colon. 


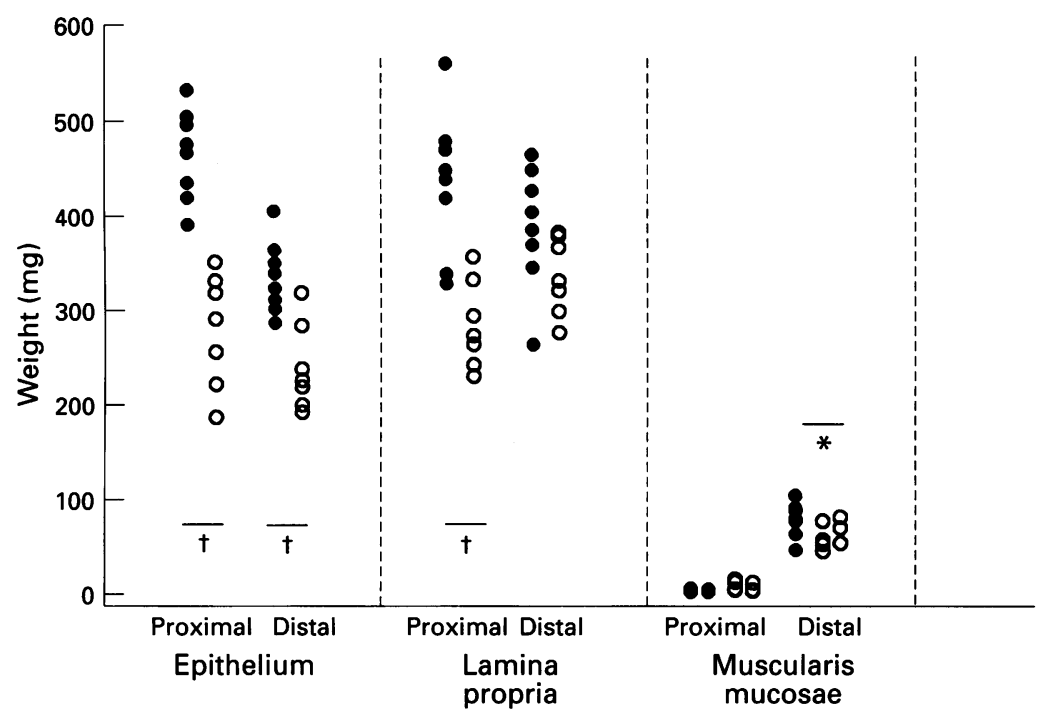

Figure 4: Weight of the epithelium, lamina propria, and muscularis mucosae in proximal and distal colon after treatment with EGF (•) and placebo (0) for 28 days. ${ }^{\star} p<0.05$, $\dagger p<0.005 E G F \mathrm{v}$ placebo. quantitative difference in the growth stimulating response to EGF treatment between mucosa of proximal and distal colon. This is interesting in view of recent studies on samples from human large bowel showing a quantitative variation in the distribution of $\mathrm{EGF}$ receptors along the length of the colon. ${ }^{23}$

A previous study on total parenteral fed rats have suggested a stimulatory effect of EGF on the colonic surface area, although these data were obtained only from selected and well orientated colon crypts. ${ }^{13}$ In our study we quantified the colonic luminal surface area in an unbiased manner and our data showed a profound surface area increase among EGF treated rats. The surface area increase seemed of equal proportions in proximal and distal colon despite a stronger effect on total mucosal weight in proximal colon segments. This might be explained by the significant effect on epithelial growth in both parts of the colon. Theoretically, the surface area growth can be caused by changes in crypt number or crypt height and diameter, but our data do not confirm this.

In addition to the effects on the mucosa, EGF treatment significantly increased the weight of the colonic submucosal layer. This is in agreement with studies that have shown biological effects of EGF on non-epithelial cells. Specific EGF receptors are found on human fibroblasts, ${ }^{24}$ and EGF treatment increases DNA synthesis and cell division in granulation tissue fibroblasts in rats. ${ }^{25} 26$ Kingsnorth et al have shown an increase in tensile strength of intestinal anastomoses in pigs under systemic EGF treatment, ${ }^{8}$ and anastomotic strength is derived mainly from collagen fibres of the submucosa. Accordingly this finding supports the idea of a growth stimulating role of EGF in the submucosal layer of intact colon. Furthermore, EGF receptors have been shown on smooth gastrointestinal muscle cells and animal studies have proposed a role for EGF in gastrointestinal muscle contractility. ${ }^{27}$ In our study, nevertheless, there were no increases in the external circular or longitudinal muscular layers of the colon.

The data regarding submucosal growth strongly show that there is a differential response in proximal and distal colon to EGF. While there was a pronounced difference and a low $\mathrm{p}$ value in distal colon with a small probability of a type I error, the EGF and placebo groups were identical in proximal colon. EGF induced stimulation of submucosal weight could result from a direct mitogen action on the fibroblasts and an increased synthesis of collagen fibres. The connective tissue of the submucosal layer also contains most of the colonic vessels, however, and submucosal growth might reflect an increase in oxygen and nutritional demands of the hypertrophic mucosa. Furthermore, EGF has been shown to possess a definite angiogenic potency and to increase granulation tissue blood flow. ${ }^{28} 29$

We used stereological methods to obtain precise, quantitative information about the transmural trophic effects of EGF. Although the stereological analyses were based on find-
Figure 5: Weight of proximal mucosa divided by the weight of distal mucosa for each animal (proximal/distal mucosal ratio) after treatment with EGF (৫) and placebo (0) for 28 days. 
ings on a limited number of colon sections, these methods do not require any assumptions regarding tissue shape or size. ${ }^{15} 19$ At the practical level during sampling and processing, however, certain simple rules were followed to assure that the information was unbiased. Sampling was done at random along the entire colon length with an equal chance for every portion of the intestine to be sampled. Equally important was the random rotation of specimens in the horizontal plane before sectioning. To account for possible variation in composition or surface area along the length of proximal and distal segments we took four or five samples from each. The variability in volume fraction and surface area estimations between these samples turned out to be small (data not shown) and we could have obtained reliable results using fewer samples. A high counting efficacy in stereological methodology gives a low variability after spending a moderate amount of time and is important in reducing the labour in studies larger than ours. ${ }^{19}$

In conclusion, the reported data show that longterm EGF treatment has a trophic effect on the normal rat colon and stimulates growth in both the mucosal and the submucosal layers. Increase in mucosal weight and luminal surface area occurs along the entire large bowel. Mucosal growth seems most eminent in proximal colon, whereas the submucosal growth is restricted to the distal colon.

We thank Mrs A Larsen for her technical assistance and Dr S Laurberg and Professor H J G Gundersen for valuable comments on the manuscript. The human recombinant EGF was a generous gift from Professor Esam Z Dajani, was a generous gift from Professor Esam Z Dajani, International Drug Development Consultants,
Mid Gulf USA Inc, Long Grove, Illinois, USA.

1 Prigent SA, Lemoine NR. The type 1 (EGFR-related) family of growth factor receptors and their ligands. Prog Growth Factor Res 1992; 4: 1-24.

2 Burgess AW. Epidermal growth factor and transforming growth factor alpha. BrMed Bull 1989; 45: 401-24.

3 Thompson JS, Saxena SK, Greaton C, Schultz G, Sharp JG. The effect of the route of delivery of urogastrone on intestinal regeneration. Surgery 1989; 106: 45-51.

4 Juhl CO, Jensen LS, Steiniche T, Moussa E. Recombinant human epidermal growth factor prevents sclerotherapyinduced esophageal ulcer and stricture formation in pigs. Dig Dis Sci 1994; 32: 393-401.

5 Konturek SJ, Dembinski A, Warzecha Z, Brozowski T, Gregory $\mathrm{H}$. Role of epidermal growth factor in healing of chronic gastroduodenal ulcers in rats. Gastroenterology 1988; 94: 1300-7.

6 Procaccino F, Reinshagen M, Hoffmann P, Zeeh JM, Lakshmanan J, McRoberts JA, et al. Protective effect of epidermal growth factor in an experimental model of colitis in rats. Gastroenterology 1994; 107: 12-7.

7 Luck MS, Bass P. Effect of epidermal growth factor on experimental colitis in the rat. $\mathcal{F}$ Pharmacol Exp Ther 1993; 264: 984-90.

8 Kingsnorth AN, Vowles R, Nash JRG. Epidermal growth factor increases tensile strength in intestinal wounds in pigs. Br f Surg 1990; 77: 409-12.

9 Walker-Smith JA, Phillips AD, Walford N, Gregory H, Fitzgerald JD, MacCullagh $\mathrm{K}$, et al. Intravenous epidermal growth factor/urogastrone increases small-intestinal cell proliferation in congenital microvilous atrophy. Lancet 1985; ii: 1239-40.

10 Drumm B, Cutz E, Tomkins KB, Cook D, Hamilton JRE, Sherman P. Urogastrone/epidermal growth factor in treatment of congenital microvillous atrophy. Lancet 1988; i: $111-2$.

11 Sullivan PB, Brueton MJ, Tabara ZB, Goodlad RA, Lee CY, Wright NA. Epidermal growth factor in necrotising colitis. Lancet 1991; 338: 53-4.

12 Foster HMcA, Whitehead RH. Intravenous but not intracolonic epidermal growth factor maintains colonocyte proliferation in defunctioned rat colorectum. Gastroenterology 1990; 99: 1710-4.

13 Goodlad RA, Lee CY, Wright NA. Cell proliferation in the small intestine and colon of intravenously fed rats: effects of urogastrone-epidermal growth factor. Cell Prolif 1992; 25: 393-404

14 Goodlad RA, Wilson TJG, Lenton W, Gregory H, McCullagh KG, Wright NA. Intravenous but not intragastric urogastrone-EGF is trophic to the intestine of parenterally fed rats. Gut 1987; 28: 573-82.

15 Kissmeyer-Nielsen $P$, Christensen H, Laurberg S. Diverting colostomy induces mucosal and muscular atrophy in rat distal colon. Gut 1994; 35: 1275-81.

16 Lindström CG, Rosengren J-E, Fork FT. Colon of the rat. Acta Radiol 1979; 20: 523-36.

17 Baddeley AJ, Gundersen HJG, Cruz-Orive LM. Estimation of surface area from vertical sections. $\mathcal{F}$ Microsc 1986; 142: 259-76.

18 Ladekarl $M$. The influence of tissue processing on quantitative histopathology in breast cancer. $\mathcal{F}$ Microsc $1994 ; 174$ : 93-100.

19 Gundersen HJG, Bendtsen TF, Korbo L, Marcussen N, Møller A, Nielsen K, et al. Some new, simple and efficient stereological methods and their use in pathological research and diagnosis. APMIS 1988; 96: 379-94.

20 Vinter-Jensen L, Smerup M, Jørgensen PE, Juhl CO, Ørntoft T, Poulsen SS, et al. Chronic treatment in the rat with epidermal growth factor stimulates growth of the urinary tract. Urol Res (in press).

21 Carpenter G, Cohen S. Human epidermal growth factor and the proliferation of human fibroblasts. F Cell Physiol 1976; 88: 227-38.

22 Marti U, Burwen SJ, Jones AL. Biological effects of epidermal growth factor, with emphasis on the gastrointestinal mal growth factor, with emphasis on the gastrointestinal

23 Koenders PG, Peters WH, Wobbes T, Beex LV, Nagengast FM, Benraad TJ. Epidermal growth factor receptor levels are lower in carcinomatous than in normal colorectal tissue. $B r f$ Cancer 1992; 65: 189-92.

24 Hollenberg MD, Cuatrecasas P. Insulin and epidermal growth factor. Human fibroblast receptors related to deoxy ribonucleic acid synthesis and amino acid uptake. $\mathcal{F}$ Biol Chem 1975; 250: 3845-53.

25 Laato M, Niinikoski J, Lundberg C, Arfors K-E. Effect of epidermal growth factor (EGF) on experimental granulation tissue. $₹$ Surg Res 1986; 41: 252-5.

26 Laato M, Niinikoski J, Gerdin B, Lebel L. Stimulation of wound healing by epidermal growth factor: a dosewound healing by epidermal growth factor:

27 Hollenberg MD. Growth factors and signal transduction in smooth muscle systems. In: Brody JS, Center DM, Tkachuk VA, eds. Signal transduction in lung cells. New York: Marcel Dekker, 1993: 369-90.

28 Savage CR, Cohen S. Proliferation of corneal epithelium induced by epidermal growth factor. Exp Eye Res 1973; 15: 361-6.

29 Laato $M$. Effect of epidermal growth factor (EGF) on blood flow and albumin extravasation in experimental granulation tissue. Acta Chir Scand 1986; 152: 401-5. 